\title{
Breast cancer prognostic classification in the molecular era: the role of histological grade
}

\author{
Emad A Rakha', Jorge S Reis-Filho², Frederick Baehner ${ }^{3}$, David J Dabbs ${ }^{4}$, Thomas Decker ${ }^{5}$, Vincenzo Eusebi', \\ Stephen B Fox , Shu Ichihara ${ }^{8}$, Jocelyne Jacquemier ${ }^{9}$, Sunil R Lakhani' ${ }^{10}$, José Palacios ${ }^{11}$, Andrea L Richardson ${ }^{12}$, \\ Stuart J Schnitt ${ }^{13}$, Fernando C Schmitt ${ }^{14}$, Puay-Hoon Tan ${ }^{15}$, Gary M Tse ${ }^{16}$, Sunil Badve ${ }^{17}$ and lan O Ellis ${ }^{* 1}$
}

\begin{abstract}
Breast cancer is a heterogeneous disease with varied morphological appearances, molecular features, behavior, and response to therapy. Current routine clinical management of breast cancer relies on the availability of robust clinical and pathological prognostic and predictive factors to support clinical and patient decision making in which potentially suitable treatment options are increasingly available. One of the best-established prognostic factors in breast cancer is histological grade, which represents the morphological assessment of tumor biological characteristics and has been shown to be able to generate important information related to the clinical behavior of breast cancers. Genome-wide microarray-based expression profiling studies have unraveled several characteristics of breast cancer biology and have provided further evidence that the biological features captured by histological grade are important in determining tumor behavior. Also, expression profiling studies have generated clinically useful data that have significantly improved our understanding of the biology of breast cancer, and these studies are undergoing evaluation as improved prognostic and predictive tools in clinical practice. Clinical acceptance of these molecular assays will require them to be more than expensive surrogates of established traditional factors such as histological grade. It is essential that they provide additional prognostic or predictive information above and beyond that offered by current parameters. Here, we present an analysis of the validity of histological grade as a prognostic factor and a consensus view on the significance of histological grade and its role in breast cancer classification and staging systems in this era of emerging clinical use of molecular classifiers.
\end{abstract}

\section{Introduction}

Breast cancer is the most common cancer in women and a leading cause of cancer death worldwide. Management of breast cancer relies on the availability of robust clinical and pathological prognostic and predictive factors to guide patient decision making and the selection of treatment options. In early-stage breast cancer, where the use of systemic therapy has to be determined for every patient, the three main prognostic determinants used in routine practice are lymph node (LN) status, tumor size, and histological grade. The Nottingham (Elston-Ellis) modification of the Scarff-Bloom-Richardson grading system, also known as the Nottingham Grading System (NGS) [1], is the grading system recommended by

\footnotetext{
*Correspondence: ian.ellis@nottingham.ac.uk
}

'Department of Histopathology, Nottingham University Hospitals NHS Trust, Nottingham City Hospital Campus, Hucknall Road, Nottingham, NG5 1PB, UK Full list of author information is available at the end of the article various professional bodies internationally (World Health Organization [WHO], American Joint Committee on Cancer [AJCC], European Union [EU], and the Royal College of Pathologists (UK RCPath) [2,3]).

The prognostic relevance of NGS in breast cancer was initially demonstrated in 1991 [1] and has been validated subsequently in multiple independent studies [4-14]. Since NGS has independent but equally powerful prognostic value, it has been combined with LN stage and tumor size to form prognostic indices: the Nottingham Prognostic Index (NPI) [15], which includes NGS and LN stage with equal weighting, and the Kalmar Prognostic Index [4], in which grade is given a higher-weighted value. Owing to the prognostic information provided by NGS, it has also been incorporated in algorithms (for example, Adjuvant! Online [16]) and guidelines (for example, the St. Gallen guidelines [17]) to determine the use of adjuvant chemotherapy. NGS provides a simple, inexpensive, and routinely applicable overview of the intrinsic biological characteristics and clinical behavior of tumors, adding important information to other 
significant and at least partly time-dependent prognostic factors, such as tumor size and LN status.

Although the current well-established clinical and histological factors and some well-defined biological factors (that is, hormone receptors and HER2 expression) show strong association with prognosis and outcome, there are increasing concerns that these variables are limited in their ability to capture the diversity of clinical behaviors of breast cancer and that they would not be sufficient to tailor the therapy to individual patients. In addition, the perceived subjective nature of histopathological assessment of the morphological features such as tumor grade has increased these concerns. The introduction of high-throughput technologies that survey thousands of genes and their products in a single assay, coupled with powerful analytical tools, has opened up new avenues for classifying breast cancer into biologically and clinically distinct groups based on gene expression patterns $[18,19]$ and DNA copy number alterations [20]. However, these expression profiling studies have suggested that molecular tests could perform better than the traditional histopathology and may replace it as the 'gold standard' for prognostication and prediction of response to therapy [21]. Recent studies leading to the development of the 21-gene recurrence score (trade name Oncotype DX; Genomic Health, Inc., Redwood City, CA, USA [22,23]) have highlighted the issue of subjectivity associated with histological grading and called into question the utility of histological grade as a prognostic tool. Regrettably, these results have been perceived as direct evidence that molecular tests provide an objective and reproducible assessment of prognostic features of estrogen receptor (ER)-positive breast cancers but that histopathological analyses are subjective and not reproducible.

Molecular methods undoubtedly provide prognostic and predictive information and may help identify new therapeutic targets, and the interest in molecular classifiers and their potential application is perfectly understandable. However, it is important to understand their limitations and critically evaluate their role in improving breast cancer prognostication above and beyond the traditional variables in a practical and cost-effective way $[24,25]$. The role of NGS as a simple and cost-effective method of assessment of tumor biology should not be neglected. It is also important to recognize that in countries with limited health resources, access to expensive new technologies may not be possible but that effective cost-efficient methods, such as routine histopathological evaluation, are available for all [26]. In fact, there are numerous lines of evidence to suggest that these molecular tests complement rather than replace the traditional pathological variables, such as NGS, to define the optimal therapy for patients with breast cancer.
Here, we present an overview of the current evidence of the significance of breast cancer grading in view of the availability of an increasing number of potentially alternative molecular prognostic tests. We present in a pragmatic way a comparison between NGS and recent molecular prognostic tests, taking into account evidencebased clinical and biological significance, cost-effectiveness, practicality of application in different parts of the world, and the impact of this on future plans for improvement in breast cancer prognostication and management.

\section{What is histological grade?}

Invasive carcinomas are morphologically subdivided according to their growth patterns and degree of differentiation, the latter of which reflects how closely they resemble normal breast epithelial cells. This subdivision is achieved by assessing histological type and histological grade, respectively. Although tumor type provides useful prognostic information, the majority (60\% to $75 \%$ ) of breast cancers have no special type of characteristics (that is, invasive ductal carcinoma of no special type, or NST); those special types that show distinct prognostic significance are relatively uncommon. As a consequence, the role of histological typing in clinical management decision making is currently limited [27].

Histological tumor grade is based on the degree of differentiation of the tumor tissue. In breast cancer, it refers to the semi-quantitative evaluation of morphological characteristics and is a relatively simple and lowcost method, requiring only adequately prepared hematoxylin-eosin-stained tumor tissue sections to be assessed by an appropriately trained pathologist using a standard protocol. NGS is based on the evaluation of three morphological features: (a) degree of tubule or gland formation, (b) nuclear pleomorphism, and (c) mitotic count (Figure 1). For details, see [1,2] and Supplementary Information [28].

\section{Histological grade and prognosis}

Multiple independent studies have shown that NGS has prognostic value that is equivalent to that of $\mathrm{LN}$ status [29] and greater than that of tumor size $[4,15]$. In a large study, Henson and colleagues [14], who assessed survival rates of 22,616 cases of breast cancer, demonstrated that patients with histological grade 1, stage II disease had the same survival as those with grade 3 , stage I disease. The authors also found that patients with grade 1 tumors of less than 2 $\mathrm{cm}$ in size had an excellent prognosis, with 99\% 5-year survival, even when they presented with positive LN. These results are supported by a recent study from the Nottingham group [11], which included 2,219 operable breast cancer cases with long-term follow-up. This study has demonstrated that grade is an important determinant of breast cancer outcome and complementary to LN stage 


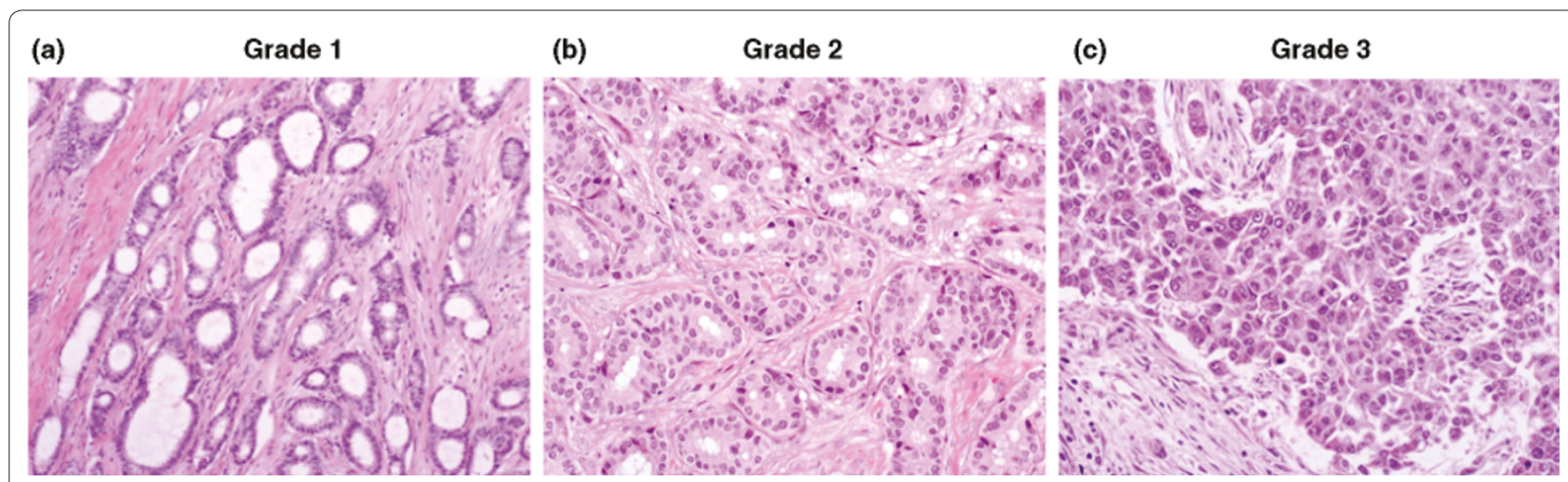

Figure 1. Histological grade of breast cancer as assessed by the Nottingham Grading System. (a) A well-differentiated tumor (grade 1) that demonstrates high homology to the normal breast terminal duct lobular unit, tubule formation $(>75 \%)$, a mild degree of nuclear pleomorphism, and low mitotic count. (b) A moderately differentiated tumor (grade 2). (c) A poorly differentiated (grade 3) tumor with a marked degree of cellular pleomorphism and frequent mitoses and no tubule formation $(<10 \%)$.

through the ability to influence the outcome of patients in different LN stage categories. These results provide evidence that histological grade, when used in conjunction with LN stage, can improve the prediction of outcome for individual patients and support its inclusion and use in multifactorial indices such as the NPI and Adjuvant! Online. Similar long-term validation has been demonstrated in screen-detected breast cancer in the Swedish Two-County Trial, which demonstrated that tumor grade, LN status, and tumor size at the time of diagnosis have a lasting influence on subsequent survival [10].

There is compelling evidence to suggest that histological grade can accurately predict tumor behavior, particularly in earlier small tumors (tumor, node, metastasis [TNM] stage $\mathrm{pT} 1$ ), more than other 'time-dependent' prognostic factors such as tumor size (pT1a, pT1b, and pT1c) $[4,9,11,15]$. Studies have also demonstrated that grade is an independent prognostic factor in specific subgroups of breast cancer, including ER-positive breast cancer patients who have not [30] or who have received neoadjuvant endocrine therapy [31] and patients with LN-negative $[5,11,13,32]$ or -positive $[7,11]$ breast cancer regardless of ER expression. Recently, Desmedt and colleagues [33] demonstrated that in the ER-positive/ HER2-negative tumors $(n=628)$, only histological grade and the proliferation module retained their association with relapse-free survival (RFS) in the multivariate analysis (hazard ratio $[\mathrm{HR}]=2.00,95 \%$ confidence interval $[\mathrm{CI}] 1.18$ to $3.37 ; P=0.01$ ). In the Nottingham series [11,34], histological grade was an independent predictor of RFS in the ER-positive/HER2-negative tumors $(\mathrm{n}=1,077)(\mathrm{HR}=2.13,95 \%$ CI 1.79 to 2.53 ; $P<0.0001)$. Similar associations between grade and survival were found in (a) the LN-negative subgroup $(\mathrm{n}=797)$, who received only adjuvant hormone therapy
$(\mathrm{HR}=1.85,95 \% \mathrm{CI} 1.46$ to $2.34 ; P<0.0001$, with rates of 10 -year risk of relapse of $7 \%$ for grade $1,14 \%$ for grade 2 , and $31 \%$ for grade 3), and in (b) ER-positive tumors with small-volume LN metastasis ( $\mathrm{pN1}$; one to three $\mathrm{LNs}$ positive $)(\mathrm{n}=316)(\mathrm{HR}=2.07,95 \% \mathrm{CI} 1.51$ to 2.86 ; $P<0.0001$, with rates of 10 -year risk of relapse of $5 \%$ for grade $1,24 \%$ for grade 2 , and $43 \%$ for grade 3 ) [11,34]. Therefore, histological grade can provide important prognostic information for clinically relevant subgroups in which the benefit of chemotherapy is less certain (for example, LN-negative/ER-positive or in patients with low-volume LN metastatic disease).

We have noted, consistently with the biological and clinical roles of histological grade on breast cancer behavior, an important association between histological grade and pattern of survival. Akin to high-grade lymphoma, high-grade breast cancers tend to recur and metastasize early following diagnosis, typically within the first 8 years; thereafter, breast cancer-related deaths decrease in frequency. Low-grade tumors tend to show a very good outcome, and few (if any) events occur; those that do occur, do so relatively late in the lifetime of the patients. Grade 2 tumors show an intermediate outcome during the early years of follow-up; however, on longterm follow-up, they show an obvious trend for continued recurrence and impaired outcome in the long term $[11,35]$ (Figure 2). In contrast, LN stage, which can provide information on the likelihood of death or survival after breast cancer, shows limited value in predicting the timescale of these events (Rakha EA, Ellis IO, unpublished data). This important observation provides further insight into the appropriate management strategies of patients with breast cancer. High-grade tumors, with their risk of early recurrence and death, require consideration for prompt use of adjuvant chemotherapy, whereas patients with grade 1 tumors, which are almost 
invariably ER-positive, could be offered a long-term follow-up with or without a potentially less toxic systemic therapy (that is, endocrine therapy).

\section{Histological grade: contentious issues}

Despite the utility of histological grade as a prognostic factor for ER-positive disease, there are numerous issues that ought to be considered for the correct use of histological grade in the management of patients with breast cancer [36-39]. These issues are detailed in the following sections.

\section{Grade and size}

The latest (7th edition) AJCC TNM staging system endorsed NGS, but grade was not included in calculating stage [40]. The decision to exclude grade as an element in the TNM staging system, as stated previously [36], is based mainly on the possible interaction between tumor size and histological grade and, in particular, the lack of clear evidence for the role of grade in small tumors (pT1 and pT2). It should be noted that two of the basic principles of breast cancer screening are that outcome of patients with small invasive cancers is good and adverse events are rare. The effect of all known prognostic factors will therefore be limited in such a patient group. However, despite this constraint, there are several lines of evidence that demonstrate the prognostic significance of NGS in small tumors. Studies that examine the prognostic significance of grade in small tumors quoted in the AJCC article by Singletary and colleagues [36] show marked variations in outcome, follow-up times, and number of patients. There was also variation in the grading method used, and information on histological grade was obtained from systematic pathology review, whereas in others, information about grade was abstracted from pathology reports, medical records, or tumor registry databases. These differences in grading systems and study design are expected to lead to different results regarding the prognostic significance not only of grade but also of other variables should they have been assessed. To conclude, although extracting consistent data on the prognostic significance of grade from the different studies cited in the AJCC review [36] is challenging, studies in which modern methods for histological grading were employed have shown that its utility is retained in small tumors [1,5,6,9,11,27,32,41-43]. With the shift that mammographic screening causes in stage distribution, this issue has become increasingly important, with a high proportion of tumors being T1NOMO at diagnosis, thereby limiting the relevance of TNM staging in routine practice.

In the Nottingham series, development of recurrent disease following diagnosis of grade 1 breast cancer was infrequent, and when observed, the recurrent lesions

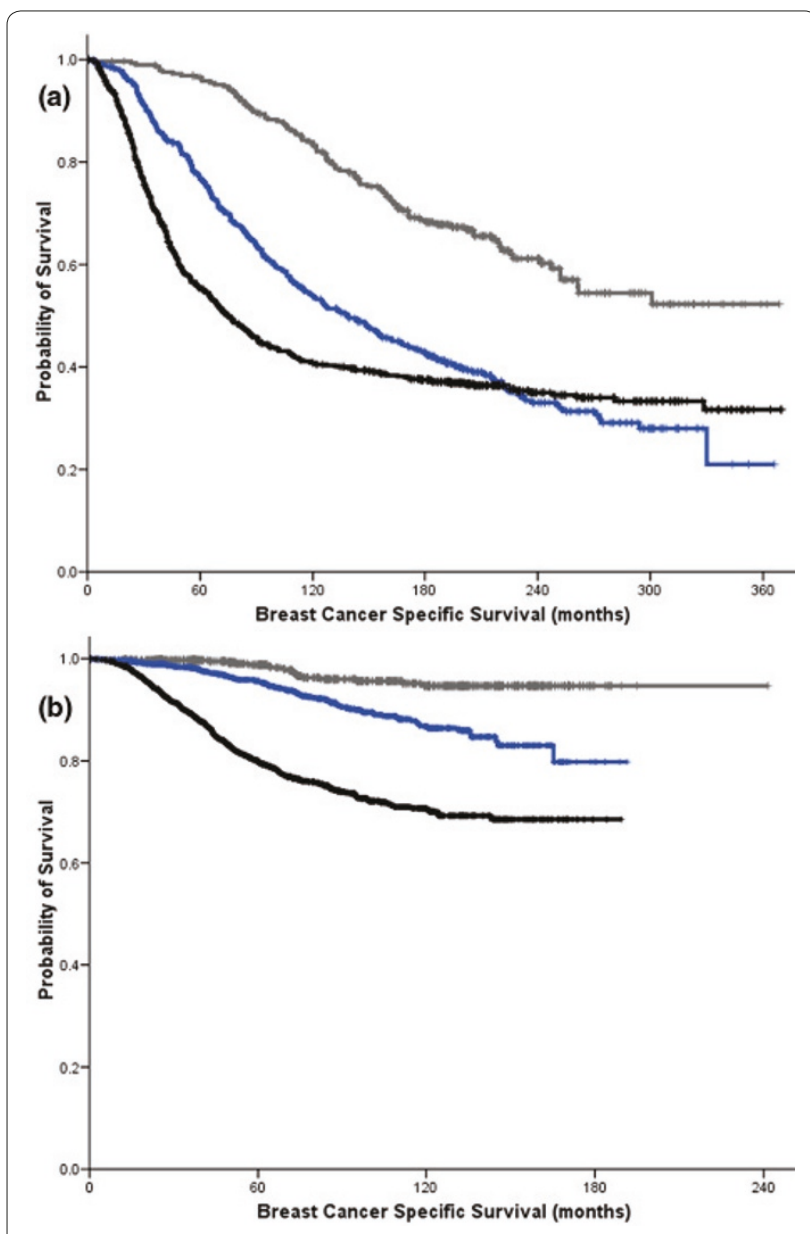

Figure 2. Relationship between histological grade and breast cancer-specific survival. (a) In the old Nottingham series (1977 to 1989), no systemic therapy was offered to the patients. Of the 1,816 patients, 404 (17.7\%) had grade 1 tumors (gray curve), 621 (36.2\%) had grade 2 (blue curve), and 791 (46.1\%) had grade 3 (black curve) $\left(X^{2}=97.5, P<0.0001\right)$. (b) In the recent Nottingham series (1990 to 2002), systemic therapy was offered to the patients according to Nottingham Prognostic Index and estrogen receptor expression as described previously [11]. Of the 3,579 patients, 677 (18.9\%) had grade 1 tumors (gray curve), 1,383 (38.6\%) had grade 2 (blue curve), and 1,519 (42.4\%) had grade 3 (black curve) $\left(X^{2}=195.5, P<0.0001\right)$. Analysis of grade 1 and 2 only showed statistical survival difference $\left(x^{2}=20.7, P<0.0001\right)$. Both series are consecutive and included estrogen receptor-positive and -negative and lymph node-negative and -positive cases $[11,75,76]$

were either higher-grade tumors or second primaries. The number of patients with grade 1 tumors who developed distant metastasis or died without developing a second event of higher-grade tumor was limited (4\%) [44]. This observation implies that grade 1 breast cancer studies that do not include pathology review and evaluation of the second event are likely to overestimate the risk of adverse outcome.

Further justification for the exclusion of grade from TNM [36] is that large tumors (pT3 and pT4) tend to be 
high-grade and nearly always carry a recommendation for adjuvant chemotherapy, irrespectively of tumor grade. Although a higher proportion of larger tumors are grade $3[8,11]$, some forms of lower-grade breast cancer such as hormone receptor-positive, low-grade invasive lobular cancers frequently present as large mammographically occult tumors and are responsive to hormone therapy. Furthermore, if tumor size/stage alone largely dictates an oncologist's choice of treatment, an argument could be made, at least in many centers, for the irrelevance of other biological variables, including gene expression signatures such as Oncotype DX, 70-gene signature, 76-gene signature, and genomic grade index (GGI). Likewise, although NGS might have limited prognostic value in HER2-positive and triple-negative cancers as most of these tumors are of high grade (grade 3) $[30,33]$, these tumors also typically exhibit poor-prognosis gene signatures [45]. In addition, molecular classifiers such as Oncotype DX and GGI [33] and the MammaPrint (Agendia, Amsterdam, The Netherlands), the last of which is recommended to all patients, have negligible discriminatory power in ER-negative disease $[30,33]$.

Therefore, we believe that treatment decisions based on TNM staging system, which measures the anatomic extent of the tumor, can be improved by the addition of histological grade, which measures the intrinsic biological features of the tumor and reflects the potential of a carcinoma to metastasize or cause death. Integration of histological grade into the relevant TNM staging system has been accepted for other common epithelial tumors such as adenocarcinoma of the prostate. As the prognostic value of NGS has been proven in operable breast cancer (stages I and II), in which decisions about systemic therapy usage and its regimen need to be made, histological grade could be incorporated in the TNM system to improve its ability to stratify cases into risk-associated subcategories corresponding to grade so that chemotherapy can be potentially be avoided in low-risk groups and considered a high priority for patients in a high-risk category. The maximum benefit of grade assessment would be in the subgroup of patients with ER-positive, LN stage N0 or N1 disease. The current evidence indicates that grading has limited value in advanced or metastatic breast cancer (stages III and VI) and grading is not expected to change treatment decisions and therefore need not be considered in these cases.

\section{Grade and tumor type}

The prognostic value of histological grade has been documented in most tumor types, including invasive lobular carcinomas [46]. Medullary carcinoma might appear to be one subtype in which grading is less significant. By definition, these tumors are of high histological grade (grade 3) but may have a more favorable prognosis than their histological grade would imply [38]. However, a recent study shows that medullary carcinomas account for less than $1 \%$ of breast cancers as a result of the strict criteria required for its recognition and that they do not have a prognosis significantly different than that of other forms of grade 3 ductal carcinoma with prominent inflammation [38]. Importantly, a recent study suggested that the 70-gene prognostic signature may also fail to provide prognostic stratification of patients with some special types of breast cancer. Given that NGS has been shown to provide prognostically relevant information for invasive ductal carcinomas of NST and lobular carcinomas, which together account for greater than $80 \%$ of all breast cancers, the systematic inclusion of histological type in breast cancer routine synoptic reports is also advocated.

\section{Grading of needle core biopsy specimens}

Current evidence suggests that histological grading can be assessed relatively reliably whereas other well-established prognostic factors, such as vascular invasion and tumor size, cannot $[47,48]$. However, some cases may be upgraded when the excision specimen is analyzed following grading of core biopsies (that is, grade I in the core biopsy and grade II in the excision specimen; $30 \%$ to $40 \%$ ). On the other hand, a diagnosis of NGS grade III in a core biopsy is not commonly changed when the excision specimen is graded (5\% to $8 \%$ ). Importantly, changes from grade I in the core to grade III in the excision specimen and vice versa are very rare (0\% to $1 \%)[47,48]$.

Selection of patients for neoadjuvant therapy requires that prognostic information be available from nonoperative diagnostic tumor samples. Amat and colleagues [49] reported that assessment of grade on needle core biopsy (NCB) is a strong predictive factor of response to induction chemotherapy in breast cancer, independently of the type of regimen used. Therefore, despite the limitations associated with the accuracy of grading core biopsies related to tumor sampling issues and visibility of mitotic figures [47,48], assessment of histological grade on $\mathrm{NCB}$ can provide information to support preoperative treatment decision making.

\section{Reproducibility of histological grade}

One of the reasons cited in the past for the reluctance to use grading in patient management decisions has been the perceived lack of reproducibility of the method. This may be highlighted by the relatively wide variation in the proportion of each grade in published series. However, a substantial number of studies have reported better levels of inter- and intra-observer concordance [1,27,50-59] (Table 1). The variation in the proportion of each grade reported in the different studies can be explained by the 
Table 1. Inter-observer and intra-observer agreement of breast cancer histological grade.

\begin{tabular}{|c|c|c|c|c|}
\hline Study & Number of cases & Number of readers & Grade & Inter-observer \\
\hline [32] & 613 & 2 & NGS & Kappa 0.69 \\
\hline [8] & 52 & 2 & NGS & Kappa 0.54 \\
\hline [55] & 425 & 2 & NGS & Complete agreement $76 \%$ \\
\hline [50] & 75 & 6 & NGS & Kappa 0.43 to 0.74 \\
\hline [51] & 12 & 600 & NGS & Kappa 0.45 to 0.53 (figures after application of guidelines) \\
\hline [52] & & 3 & NGS & Complete agreement 72.3\%; kappa 0.57 \\
\hline [53] & 24 & 21 & NGS & Complete agreement 69\%; kappa 0.53 \\
\hline [54] & 50 & 5 & NGS & Mean polychoric correlation 0.8 \\
\hline$[56]$ & 35 & 13 & NGS & Kappa 0.5 to 0.7 \\
\hline [57] & 93 & 7 & NGS & Kappa 0.54 \\
\hline$[58]$ & 40 & 3 & NGS & Kappa 0.68 to 0.83 \\
\hline [59] & 874 & 2 & WHO criteria & Complete agreement 78.1\%; kappa 0.66 \\
\hline [61] & 50 & 5 & NGS & Complete agreement 83.3\%; kappa 0.73 \\
\hline
\end{tabular}

NGS, Nottingham Grading System; WHO, World Health Organization.

variation in the grading system used and the difference in the patient cohorts, including age distribution, symptomatic versus screening population, early versus advanced breast cancer groups, and details of tissue fixation. Grading is dependent on a high quality of tissue preservation. Suboptimal levels of tissue fixation lead to disruption and loss of visibility of mitotic figures, one of the three variables assessed in NGS. Assessment of grade in poorly fixed tissue will therefore introduce a bias leading to a reduction in the proportion of cases classified as grade $3[1,2,60]$.

Another important point to improve the inter-observer agreement rates is the introduction of guidelines for standardization of pre-analytical parameters, including tissue handling, fixation, and preparation, and of the methods for tumor grading. Differences between centers can be attributed in many cases to differences in the quality of tissue preparation [2,61]. Critical evaluation of these issues and recommendations for good practice have been provided by professional organizations (that is, WHO, EU, UK RCPath, and the International Union Against Cancer [UICC]) [2]. The use of rigorously optimized and standardized methods in Nottingham has provided a high NGS reproducibility between grading of a recent series [11] and that of an old series published more than two decades ago from the same institution with a similar percentage of cases in each grade (Table 2). Significant improvements in the consistency of histological grading have been observed on a national basis in the UK through the publication of guidelines with linked educational activity and associated external quality assurance (EQA) [51]. These guidelines provide not only information on histological grading methodology but also recommendations on the application of these methods and guidance on tissue handling. Adherence to these guidelines and participation in EQA are also expected to improve assessment of other important prognostic factors in breast cancer, such as lymphovascular invasion and immunohistochemical determination of other biomarkers. In addition, the current use of NGS is expected to provide consistency among different studies in the future as evidenced from multiple studies from the Nottingham group and other institutions that endorse NGS $[2,39,60,62]$. However, despite the objective improvements that have been made to breast cancer grading methods, any assessment of morphological characteristics inevitably retains a subjective element and is heavily dependent on the pre-analytical parameters.

It should be noted that the degree of scrutiny of the inter-observer reproducibility histological grade has never been applied to molecular tests in current clinical use. A more detailed reproducibility study of the performance of gene expression studies has not been conducted as of yet. In fact, issues of reproducibility are well recognized in all forms of medical laboratory testing. Despite the undeniable need to improve the inter-observer agreement for histological grade, the criticisms directed against NGS should be tempered by the fact that other parameters used to determine the therapy of patients with breast cancer also suffer from inter-observer variability, including the assessment of small-volume nodal metastases (LN stage), HER2 immunohistochemical and in situ hybridization scoring, ER scoring, assessment of vascular invasion, and even the assessment of tumor size.

\section{Significance of grade 2 tumors}

Mis-assignments of grade I to grade III or vice versa are rarely reported, but grade II tumors usually show the 
Table 2. Proportion of grades among different studies.

\begin{tabular}{|c|c|c|c|c|}
\hline Study & Number of cases & Grade 1 & Grade 2 & Grade 3 \\
\hline Elston, 1984 [77] & 625 & $17 \%$ & $37 \%$ & $46 \%$ \\
\hline Davis et al., 1986 [78] & 1,537 & $22 \%$ & $49 \%$ & $29 \%$ \\
\hline Hopton et al., 1989 [59] & 874 & $29 \%$ & $46 \%$ & $25 \%$ \\
\hline Le Doussal et al., 1989 [79] & 1,262 & $11 \%$ & $45 \%$ & $46 \%$ \\
\hline Balslev et al., 1994 [80] & 9,149 & $32 \%$ & $49 \%$ & $19 \%$ \\
\hline Saimura et al.., 1999 [5] & 741 & 19 & $37 \%$ & $44 \%$ \\
\hline Reed et al., 2000 [32] & 613 & $25 \%$ & $41 \%$ & $35 \%$ \\
\hline Simpson et al., 2000 [7] & 368 & $22 \%$ & $45 \%$ & $33 \%$ \\
\hline Lundin et al., 2001 [6] & 1,554 & $26 \%$ & $47 \%$ & $27 \%$ \\
\hline Frkovic-Grazio and Bracko, 2002 [9] & 270 & $38 \%$ & $38 \%$ & $24 \%$ \\
\hline Warwick et al., 2004 [10] & 1,988 & $23 \%$ & $37 \%$ & $40 \%$ \\
\hline Williams et al., 2006 [26] & 1,058 & $20 \%$ & $46 \%$ & $34 \%$ \\
\hline Rakha et al., 2008 [11] & 2,219 & $18 \%$ & $36 \%$ & $46 \%$ \\
\hline Thomas et al., 2009 [81] & 1,650 & $26 \%$ & $45 \%$ & $29 \%$ \\
\hline Blamey et al., 2009 [12] & 16,944 & $29 \%$ & $41 \%$ & $30 \%$ \\
\hline
\end{tabular}

lowest degree of concordance. This is an expected phenomenon of scoring of a biological variable where scores in the overlap regions are usually most difficult to be categorised. The similar example of the problem of reproducibility of classification of a continuous biological variable was noted in the microarray-based gene expression profiling studies $[63,64]$. For example, in the studies by Sorlie and colleagues [18] and Chang and colleagues [65], only a proportion of cases could be accurately classified into the molecular subtypes, $9 \%$ to $15 \%$ of tumors could not be assigned as grade 1 and grade 3 by GGI [66], and $19 \%$ to $24 \%$ of cases showed discordance among different gene expression signatures applied to the same set of tumors [45].

In the latest meeting of the St. Gallen International Expert Consensus on the Primary Therapy of Early Breast Cancer (2009) [17], it was recommended that grade 1 and grade 3 be taken into consideration for the assessment of indications of adjuvant chemotherapy. Grade 2 was regarded as being similar to other parameters of intermediate-risk significance, such as tumor size of between 2 and $5 \mathrm{~cm}$, low numbers (one to three) of involved LNs, and intermediate scores on multigene assays, and it was inferred that they do not provide a definitive indication of risk with respect to the clinical decision of whether to give or withhold chemotherapy. However, it was also noted that the presence of these intermediate-risk criteria usually tips the balance toward the use of chemotherapy [17].

The advantage of applications of molecular tests as complements to grade is particularly evident with respect to grade 2 tumors. Several attempts have been made to improve biological and clinical significance of histological grading by classifying grade 2 tumors into two distinct subclasses: a grade 1-like subgroup, which has an excellent outcome and may not require adjuvant chemotherapy, and a grade 3-like subgroup, which comprises tumors that behave in a way similar to high-grade cancers and need a more aggressive systemic treatment. Examples of these studies include the application of GGI to subclassify histological grade 2 into two molecular subclasses (GGI1 and GGI3) [66] or the use of proliferation biomarkers such as MIB1 (Ki67) expression (Rakha EA, Ellis IO, unpublished data). However, the clinical usefulness and the cost-benefit ratios of these studies need to be further evaluated if they are to be translated into routine practice worldwide, particularly in countries with limited resources.

\section{Grade and molecular profiling}

Recent profiling studies of breast cancer have emphasized the relevance of tumor biology in governing breast cancer behavior and hence the importance of histological grade. Tumors of different histological grades show distinct molecular profiles at the genomic, transcriptomic, and immunohistochemical levels. These results suggest that the majority of high-grade tumors are unlikely to stem from the progression of low-grade cancers and that grade 1 and 3 breast tumors are probably different diseases [67].

Gene expression studies have demonstrated that histological grade better reflects the molecular makeup of breast cancer than LN status and tumor size do [68,69]. Sotiriou and colleagues [66] developed a 97-gene classifier that can accurately identify cases diagnosed as NGS I or NGS III. Their studies have shown an association between a 'gene signature' developed to recapitulate 
histological grade (GGI) of breast cancer and patient outcome, independently of LN status or tumor size [66]. This assay is currently being commercialized in Europe (MapQuant Dx; Ipsogen, Marseille, France). When the prognostic performance of GGI was compared with the Oncotype DX [22] and 70- and 76-gene signatures, a similar separation in distant metastasis-free survival between low- and high-risk groups by the three signatures was found [45]. Another group has similarly demonstrated that the genetic grade signature (RNAbased) remained significantly associated with disease recurrence in most cases.

However, recent meta-analyses of microarray-based expression profiling studies have demonstrated that the prognostic impact of the signatures investigated stems from the proliferation-related genes [30,33]. In fact, when several of the published signatures were divided into partial signatures composed of proliferation-related genes and genes not related to proliferation, the latter failed to show prognostic significance, whereas the prognostic power of some signatures even improved by the removal of genes not related to proliferation [30]. Most importantly, in numerous studies using molecular signatures, histological grade remained an independent prognostic factor for ER-positive tumors even after the inclusion of gene signatures in the multivariate models $[22,25]$.

There are several lines of evidence to suggest that the objective contribution of gene signatures above and beyond the current clinicopathological parameters is limited. Dunkler and colleagues [70] demonstrated that the explained variation of prognosis (that is, the proportion of patients whose prognosis is determined solely by a given parameter) by prognostic signatures is limited (for example, $3 \%$ for the 70 -gene signature) when grade and other clinicopathological variables such as LN stage, patient age, and ER status are included in the survival models [30,70,71]. It is important to mention, however, that there are relatively few head-to-head comparisons of NGS versus molecular signatures and that most of them so far have a competitive tone to them. Studies that combine molecular assays and NGS in a balanced manner would be warranted.

\section{Grade in the era of molecular profiling tests}

Prognostic molecular tests for patients with breast cancer, including Oncotype DX [22] and MammaPrint [72], have already been approved for clinical use. Undoubtedly, these assays support breast cancer prognostication and can be used as a complement to the wellestablished variables currently used in routine practice [73], as recently recommended in the St. Gallen guidelines [17].

The cost of MammaPrint and Oncotype DX [74] is orders of magnitude higher than that of histological grading. Oncotype DX has undergone health economic evaluation in the US and has been reported to be costbeneficial through reduction of widespread use and appropriate targeting of use of adjuvant chemotherapy. In countries or centers where chemotherapy is less widely prescribed or where targeting is based on other tests, there may be a reduced benefit and justification of the test cost [26]. There is a trend in the research community not to consider cost-effectiveness when promoting the use of a newly developed molecular test, even though costs typically are taken into consideration when evaluating new interventions [26,74]. The costs of these modern assays are likely to remain high, and it should be borne in mind that there are still many parts of the world that do not and will not have ready access to these costly tests. Therefore, histological grading, when carried out properly on well-fixed specimens, provides a simple, inexpensive, and highly accurate alternative method for assessing tumor biological characteristics and patient prognosis and identifying patients at high and low risk for adverse outcomes. In addition, the cost and availability are not the only factors limiting the routine applicability of currently approved or recommended molecular prognostic assays as there may also be some skepticism of the scientific rigor of industry-sponsored cost-benefit economic models.

Given that grade has been shown by multiple independent groups to be prognostic and that the levels of interobserver agreement have increased with the adoption of NGS, it is rather surprising that clinical practice has changed with molecular tests that have not been as comprehensively tested but has not changed with NGS. Possibly, this stems from the purported objectivity of molecular tests and the denounced subjectivity of histopathological analysis [25]. However, molecular tests also suffer from subjectivity in terms of the biostatistical approaches employed, the stability of the molecular subgroups identified by the tests, and the reproducibility of assays performed with cell extracts without careful microdissection of tumor cells (that is, contamination with normal breast epithelial cells or proliferating stromal cells may change the results of molecular tests based on the assessment of ER- and proliferation-related genes) [25]. Therefore, it should be recognized that both molecular assays and NGS have their own strengths and weaknesses, which vary in different situations. Both can provide valuable prognostic information and both should complement rather than compete with each other and this should be understood when they are used for patient management decision making. When used in combination, molecular tests such as GGI are potentially important in the subclassification of grade 2 breast tumors. However, the application of molecular tests to known grade 1 and grade 3 breast cancers in the treatment 
decision-making process may need further validation and confirmation of any additional prognostic value and cost benefit.

\section{Conclusions}

There is an international consensus that NGS should be considered the 'gold standard' for breast cancer grading. The adoption of the objective criteria of NGS has been shown to overcome many of the previous problems of reproducibility of grading, problems that resulted from using a variety of approaches. To provide a consistent and uniform way of assessing histological grade and to improve its reproducibility, consensus criteria and guidelines have been published with critical evaluation of these issues and recommendations for good practice [2]. Strict adherence to these criteria is expected to improve consistency and reproducibility of breast cancer grading among different institutions. Histological grading, when adequately carried out, provides a simple, inexpensive, and highly accurate method for assessing tumor biological characteristics and patient prognosis. This is of particular importance for breast cancer patients in parts of the world where access to new molecular technology is not currently available. Molecular assays and NGS should complement rather than compete with each other. We conclude that the assessment of histological grade is an important determinant of breast cancer prognostication and should be incorporated in staging systems and in algorithms to define therapy for patients with breast cancer.

\section{Take-home messages}

The Nottingham Grading System, when adequately carried out, provides a simple, inexpensive, accurate, and validated method for assessing patient prognosis.

Consensus criteria for histological grading and recommendations for good practice have been published $[2,51]$ and should be followed.

The Nottingham Grading System is a validated alternative to molecular tests in parts of the world where access to new molecular technology is not currently available or likely to become available in the near future.

Assessment of histological grade is an important determinant of breast cancer prognostication and should be incorporated in algorithms to define therapy for patients with breast cancer.

\section{Search strategy and selection criteria}

Literature databases, including PubMed, Medline, and the Cochrane Library, were searched for articles published from 1980 to 2009 in English. The keywords used for the search were 'breast cancer', 'grade', 'histologic(al) grade,' 'molecular profile', and 'reproducibility' in relation to biology, prognosis, prediction, and patient outcome. Articles published before 1980 or in another language were also considered if they were commonly referenced or were highly regarded older publications. The search also included the references list for these articles and selected additional articles and webpages that were judged to be relevant. Data from publications submitted as abstracts were excluded.

\section{Abbreviations \\ AJCC, American Joint Committee on Cancer; Cl, confidence interval; EQA, external quality assurance; ER, estrogen receptor; EU, European Union; GGl, genomic grade index; HR, hazard ratio; LN, lymph node; NCB, needle core biopsy; NGS, Nottingham Grading System; NPI, Nottingham Prognostic Index; NST, no special type; RFS, relapse-free survival; TNM, tumor, node, metastasis; UK RCPath, Royal College of Pathologists; WHO, World Health Organization.}

\section{Competing interests}

The authors declare that they have no competing interests.

\section{Authors' contributions}

EAR and JSR-F performed the literature review and helped write the first draft of the manuscript. SB and IOE helped write the first draft. All authors contributed to the writing and approval of the final and revised drafts of the manuscript.

\section{Acknowledgments}

On 16 October 2008, the Susan G Komen for the Cure sponsored a meeting of pathologists to review and make recommendations regarding the utility of histological grade in breast cancer staging and prognostication. This report was conceived in that meeting. JSR-F is funded in part by Breakthrough Breast Cancer. The funding sources had no role in the literature search or in the drafting and approval of the manuscript.

\section{Author details}

'Department of Histopathology, Nottingham University Hospitals NHS Trust, Nottingham City Hospital Campus, Hucknall Road, Nottingham, NG5 1PB, UK; ${ }^{2} T$ he Breakthrough Breast Cancer Research Centre, Institute of Cancer Research, Fulham Road, London, SW3 6JB, UK; ${ }^{3}$ Department of Anatomic Pathology, University of California, Divisadero Street, Box 1785, San Francisco, CA 94143, USA; ${ }^{4}$ University of Pittsburgh Medical Center, Halket Street, Pittsburgh, PA 15213, USA; ${ }^{5}$ Breast-Screening-Pathology, Reference Centre Münster, Gerhard Domagk-Institute of Pathology, University Hospital Münster, Domagkstrasse 17, D-48149 Münster, Germany; ${ }^{6}$ Sezione Anatomia Istologia e Citologia Patologica 'M. Malpighi', Università-ASL Ospedale Bellaria, Via Altura 3, 40139 Bologna, Italia; ${ }^{\top}$ Pathology Department, Peter MacCallum Cancer Centre, St Andrews Place, East Melbourne, Victoria 3002, Australia; ${ }^{8}$ Department of Pathology, Nagoya Medical Center 4-1-1 Sannomaru, Naka ku, Nagoya 4600001 , Japan; 'Unité d'Anatomie et de Cytologie Pathologiques, Institut Paoli-Calmettes, 13273 Marseille, Cedex 9, France; ${ }^{10}$ Molecular and Cellular Pathology, The University of Queensland, Mayne Medical School, Brisbane, QLD 4006, Australia; "Servicio de Anatomía Patológica, Hospital Universitario Virgen del Rocío, Avda. Manuel Siurot, s/n, 41013 Sevilla, Spain; ${ }^{12}$ Department of Pathology, Brigham and Women's Hospital, Harvard Medical School, Boston, MA 02115, USA; ${ }^{13}$ Department of Pathology, Beth Israel Deaconess Medical Center and Harvard Medical School, 330 Brookline Avenue, \#SI435, Boston, MA 02215, USA; ${ }^{14}$ Institute of Molecular Pathology and Immunology (IPATIMUP) and Medical Faculty, University of Porto, R. Roberto Frias, S/N, 4200 - Porto, Portugal; ${ }^{15}$ Department of Pathology, Singapore General Hospital, Outram Road, Singapore $169608 ;{ }^{16}$ Department of Anatomical and Cellular Pathology, Prince of Wales Hospital, Ngan shing Street, Shatin, Hong Kong; ${ }^{17}$ Departments of Pathology and Internal Medicine, Clarian Pathology Lab of Indiana University, 350 West 11 th Street, CPL-4050, Indianapolis, IN 46202, USA.

\section{Published: 24 August 2010}

\section{References}

1. Elston CW, Ellis IO: Pathological prognostic factors in breast cancer I. The value of histological grade in breast cancer: experience from a large study with long-term follow-up. Histopathology 1991, 19:403-410.

2. Pathology Reporting of Breast Disease: A Joint Document Incorporating the Third 
Edition of the NHS Breast Screening Programme's Guidelines for Pathology Reporting in Breast Cancer Screening and the Second Edition of The Royal College of Pathologists' Minimum Dataset for Breast Cancer Histopathology. Sheffield; NHS Cancer Screening Programmes and The Royal College of Pathologists; January 2005

3. Tavassoli FA, Devilee P: World Health Organization classification of tumours. In Pathology and Genetics Tumours of the Breast and Female Genital Organs. Lyon: IARC Press; 2003:19-23.

4. Sundquist M, Thorstenson S, Brudin L, Nordenskjold B: Applying the Nottingham Prognostic Index to a Swedish breast cancer population. South East Swedish Breast Cancer Study Group. Breast Cancer Res Treat 1999, 53:1-8.

5. Saimura M, Fukutomi T, Tsuda H, Sato H, Miyamoto K, Akashi-Tanaka S, Nanasawa T: Prognosis of a series of 763 consecutive node-negative invasive breast cancer patients without adjuvant therapy: analysis of clinicopathological prognostic factor. J Surg Oncol 1999, 71:101-105.

6. Lundin J, Lundin M, Holli K, Kataja V, Elomaa L, Pylkkanen L, TurpeenniemiHujanen T, Joensuu $\mathrm{H}$ : Omission of histologic grading from clinical decision making may result in overuse of adjuvant therapies in breast cancer: results from a nationwide study. J Clin Oncol 2001, 19:28-36.

7. Simpson JF, Gray R, Dressler LG, Cobau CD, Falkson Cl, Gilchrist KW, Pandya KJ, Page DL, Robert NJ: Prognostic value of histologic grade and proliferative activity in axillary node-positive breast cancer: results from the Eastern Cooperative Oncology Group Companion Study, EST 4189. J Clin Oncol 2000, 18:2059-2069

8. Anderson TJ, Alexander FE, Lamb J, Smith A, Forrest AP: Pathology characteristics that optimize outcome prediction of a breast screening trial. Br J Cancer 2000, 83:487-492.

9. Frkovic-Grazio S, Bracko M: Long term prognostic value of Nottingham histological grade and its components in early (PT1NOMO) breast carcinoma. J Clin Pathol 2002, 55:88-92.

10. Warwick J, Tabar L, Vitak B, Duffy SW: Time-dependent effects on survival in breast carcinoma: results of 20 years of follow-up from the Swedish Two-County Study. Cancer 2004, 100:1331-1336.

11. Rakha EA, El-Sayed ME, Lee AH, Elston CW, Grainge MJ, Hodi Z, Blamey RW, Ellis IO: Prognostic significance of nottingham histologic grade in invasive breast carcinoma. J Clin Oncol 2008, 26:3153-3158.

12. Blamey RW, Hornmark-Stenstam B, Ball G, Blichert-Toft M, Cataliotti L, Fourquet A, Gee J, Holli K, Jakesz R, Kerin M, Mansel R, Nicholson R, Pienkowski T, Pinder S, Sundquist M, van de Vijver M, Ellis I: ONCOPOOL A European database for 16,944 cases of breast cancer. Eur J Cancer 2010, 46:56-71.

13. Mirza AN, Mirza NQ, Vlastos G, Singletary SE: Prognostic factors in nodenegative breast cancer: a review of studies with sample size more than 200 and follow-up more than 5 years. Ann Surg 2002, 235:10-26.

14. Henson DE, Ries L, Freedman LS, Carriaga M: Relationship among outcome, stage of disease, and histologic grade for 22,616 cases of breast cancer. The basis for a prognostic index. Cancer 1991, 68:2142-2149.

15. Galea MH, Blamey RW, Elston CE, Ellis IO: The Nottingham Prognostic Index in primary breast cancer. Breast Cancer Res Treat 1992, 22:207-219.

16. Mook S, Schmidt MK, Rutgers EJ, van de Velde AO, Visser O, Rutgers SM, Armstrong N, van't Veer LJ, Ravdin PM: Calibration and discriminatory accuracy of prognosis calculation for breast cancer with the online Adjuvant! program: a hospital-based retrospective cohort study. Lancet Oncol 2009, 10:1070-1076.

17. Goldhirsch A, Ingle JN, Gelber RD, Coates AS, Thurlimann B, Senn HJ: Thresholds for therapies: highlights of the St Gallen International Expert Consensus on the primary therapy of early breast cancer 2009. Ann Oncol 2009, 20:1319-1329.

18. Sorlie T, Tibshirani R, Parker J, Hastie T, Marron JS, Nobel A, Deng S, Johnsen H, Pesich R, Geisler S, Demeter J, Perou CM, Lønning PE, Brown PO, BørresenDale AL, Botstein D: Repeated observation of breast tumor subtypes in independent gene expression data sets. Proc Natl Acad Sci U S A 2003, 100:8418-8423.

19. Sotiriou C, Neo SY, McShane LM, Korn EL, Long PM, Jazaeri A, Martiat P, Fox SB, Harris AL, Liu ET: Breast cancer classification and prognosis based on gene expression profiles from a population-based study. Proc Natl Acad Sci U S A 2003, 100:10393-10398.

20. Chin K, DeVries S, Fridlyand J, Spellman PT, Roydasgupta R, Kuo WL, Lapuk A, Neve RM, Qian Z, Ryder T, Chen F, Feiler H, Tokuyasu T, Kingsley C, Dairkee S, Meng Z, Chew K, Pinkel D, Jain A, Ljung BM, Esserman L, Albertson DG,
Waldman FM, Gray JW: Genomic and transcriptional aberrations linked to breast cancer pathophysiologies. Cancer Cell 2006, 10:529-541.

21. Peppercorn J, Perou CM, Carey LA: Molecular subtypes in breast cancer evaluation and management: divide and conquer. Cancer Invest 2008, 26:1-10.

22. Paik S, Shak S, Tang G, Kim C, Baker J, Cronin M, Baehner FL, Walker MG, Watson D, Park T, Hiller W, Fisher ER, Wickerham DL, Bryant J, Wolmark N: A multigene assay to predict recurrence of tamoxifen-treated, nodenegative breast cancer. N Engl J Med 2004, 351:2817-2826.

23. Paik S, Tang G, Shak S, Kim C, Baker J, Kim W, Cronin M, Baehner FL, Watson D, Bryant J, Costantino JP, Geyer CE Jr., Wickerham DL, Wolmark N: Gene expression and benefit of chemotherapy in women with node-negative, estrogen receptor-positive breast cancer. J Clin Oncol 2006, 24:3726-3734.

24. Correa Geyer F, Reis-Filho JS: Microarray-based gene expression profiling as a clinical tool for breast cancer management: are we there yet? Int J Surg Pathol 2009, 17:285-302.

25. Weigelt B, Baehner FL, Reis-Filho JS: The contribution of gene expression profiling to breast cancer classification, prognostication and prediction: a retrospective of the last decade. J Pathol 2010, 220:263-280.

26. Williams C, Brunskill S, Altman D, Briggs A, Campbell H, Clarke M, Glanville J, Gray A, Harris A, Johnston K, Lodge M: Cost-effectiveness of using prognostic information to select women with breast cancer for adjuvant systemic therapy. Health Technol Assess 2006, 10:iii-iv, ix-xi, 1-204.

27. Pereira H, Pinder SE, Sibbering DM, Galea MH, Elston CW, Blamey RW, Robertson JF, Ellis IO: Pathological prognostic factors in breast cancer. IV: Should you be a typer or a grader? A comparative study of two histological prognostic features in operable breast carcinoma. Histopathology 1995, 27:219-226.

28. Assessment of breast cancer grading using the Nottingham combined histological grading system [http://www.nottingham.ac.uk/ mrzarg/nott. htm].

29. Walker RA: Prognostic and Predictive Factors in Breast Cancer. 1st edition. New York: Informa Health Care; 2003.

30. Wirapati P, Sotiriou C, Kunkel S, Farmer P, Pradervand S, Haibe-Kains B, Desmedt C, lgnatiadis M, Sengstag T, Schütz F, Goldstein DR, Piccart M, Delorenzi M: Meta-analysis of gene expression profiles in breast cancer: toward a unified understanding of breast cancer subtyping and prognosis signatures. Breast Cancer Res 2008, 10:R65.

31. Ellis MJ, Tao Y, Luo J, A'Hern R, Evans DB, Bhatnagar AS, Chaudri Ross HA, von Kameke A, Miller WR, Smith I, Eiermann W, Dowsett M: Outcome prediction for estrogen receptor-positive breast cancer based on postneoadjuvant endocrine therapy tumor characteristics. J Nat/ Cancer Inst 2008, 100:1380-1388.

32. Reed W, Hannisdal E, Boehler PJ, Gundersen S, Host H, Marthin J: The prognostic value of $\mathrm{p} 53$ and c-erb B-2 immunostaining is overrated for patients with lymph node negative breast carcinoma: a multivariate analysis of prognostic factors in 613 patients with a follow-up of 14-30 years. Cancer 2000, 88:804-813.

33. Desmedt C, Haibe-Kains B, Wirapati P, Buyse M, Larsimont D, Bontempi G, Delorenzi M, Piccart M, Sotiriou C: Biological processes associated with breast cancer clinical outcome depend on the molecular subtypes. Clin Cancer Res 2008, 14:5158-5165.

34. Rakha EA, El-Sayed ME, Green AR, Paish EC, Powe DG, Gee J, Nicholson RI, Lee $\mathrm{AH}$, Robertson JF, Ellis IO: Biologic and clinical characteristics of breast cancer with single hormone receptor positive phenotype. J Clin Oncol 2007, 25:4772-4778.

35. Rakha EA, El-Sayed ME, Powe DG, Green AR, Habashy H, Grainge MJ, Robertson JF, Blamey R, Gee J, Nicholson RI, Lee AH, Ellis IO: Invasive lobular carcinoma of the breast: Response to hormonal therapy and outcomes. Eur J Cancer 2008, 44:73-83.

36. Singletary SE, Allred C, Ashley P, Bassett LW, Berry D, Bland KI, Borgen PI, Clark G, Edge SB, Hayes DF, Hughes LL, Hutter RV, Morrow M, Page DL, Recht A, Theriault RL, Thor A, Weaver DL, Wieand HS, Greene FL: Revision of the American Joint Committee on Cancer staging system for breast cancer. J Clin Oncol 2002, 20:3628-3636.

37. Pedersen L, Zedeler K, Holck S, Schiodt T, Mouridsen HT: Medullary carcinoma of the breast. Prevalence and prognostic importance of classical risk factors in breast cancer. Eur J Cancer 1995, 31A:2289-2295.

38. Rakha EA, El-Sayed ME, Reed J, Lee AH, Evans AJ, Ellis IO: Screen-detected breast lesions with malignant needle core biopsy diagnoses and no malignancy identified in subsequent surgical excision specimens 
(potential false-positive diagnosis). Eur J Cancer 2009, 45:1162-1167.

39. Fitzgibbons PL, Page DL, Weaver D, Thor AD, Allred DC, Clark GM, Ruby SG, O'Malley F, Simpson JF, Connolly JL, Hayes DF, Edge SB, Lichter A, Schnitt SJ: Prognostic factors in breast cancer. College of American Pathologists Consensus Statement 1999. Arch Pathol Lab Med 2000, 124:966-978.

40. Edge SB, Byrd DR, Compton CC, Fritz AG, Greene FL, Trotti A: AJCC Cancer Staging Manual. 7th edition. New York: Springer; 2010.

41. Hanrahan EO, Valero V, Gonzalez-Angulo AM, Hortobagyi GN: Prognosis and management of patients with node-negative invasive breast carcinoma that is $1 \mathrm{~cm}$ or smaller in size (stage 1;T1a,bNOMO): a review of the literature. J Clin Oncol 2006, 24:2113-2122.

42. Rivadeneira DE, Simmons RM, Christos PJ, Hanna K, Daly JM, Osborne MP: Predictive factors associated with axillary lymph node metastases in T1a and T1b breast carcinomas: analysis in more than 900 patients. J Am Coll Surg 2000, 191:1-6; discussion 6-8.

43. Kollias J, Murphy CA, Elston CW, Ellis IO, Robertson JF, Blamey RW: The prognosis of small primary breast cancers. Eur J Cancer 1999, 35:908-912

44. Rakha EA, Lee AH, Evans AJ, Menon S, Assad NY, Hodi Z, Macmillan D, Blamey RW, Ellis IO: Tubular carcinoma of the breast: further evidence to support its excellent prognosis. J Clin Oncol 2010, 28:99-104.

45. Fan C, Oh DS, Wessels L, Weigelt B, Nuyten DS, Nobel AB, van't Veer LJ, Perou $\mathrm{CM}$ : Concordance among gene-expression-based predictors for breast cancer. N Eng/ J Med 2006, 355:560-569.

46. Rakha EA, El-Sayed ME, Menon S, Green AR, Lee AH, Ellis IO: Histologic grading is an independent prognostic factor in invasive lobular carcinoma of the breast. Breast Cancer Res Treat 2008, 111:121-127.

47. Denley H, Pinder SE, Elston CW, Lee AH, Ellis IO: Preoperative assessment of prognostic factors in breast cancer. J Clin Pathol 2001, 54:20-24

48. Rakha EA, Ellis IO: An overview of assessment of prognostic and predictive factors in breast cancer needle core biopsy specimens. J Clin Pathol 2007, 60:1300-1306.

49. Amat S, Penault-Llorca F, Cure H, Le Bouedec G, Achard JL, Van Praagh I, Feillel V, Mouret-Reynier MA, Dauplat J, Chollet P: Scarff-Bloom-Richardson (SBR) grading: a pleiotropic marker of chemosensitivity in invasive ductal breast carcinomas treated by neoadjuvant chemotherapy. Int J Oncol 2002, 20:791-796

50. Frierson HF Jr., Wolber RA, Berean KW, Franquemont DW, Gaffey MJ, Boyd JC, Wilbur DC: Interobserver reproducibility of the Nottingham modification of the Bloom and Richardson histologic grading scheme for infiltrating ductal carcinoma. Am J Clin Pathol 1995, 103:195-198.

51. Ellis IO, Coleman D, Wells C, Kodikara S, Paish EM, Moss S, Al-Sam S, Anderson N, Bobrow L, Buley I, Connolly CE, Dallimore NS, Hales S, Hanby A, Humphreys S, Knox F, Lowe J, Macartney J, Nash R, Parham D, Patnick J, Pinder SE, Quinn CM, Robertson AJ, Shrimankar J, Walker RA, Winder R: Impact of a national external quality assessment scheme for breast pathology in the UK. J Clin Pathol 2006, 59:138-145

52. Theissig F, Kunze KD, Haroske G, Meyer W: Histological grading of breast cancer. Interobserver, reproducibility and prognostic significance. Pathol Res Pract 1990, 186:732-736

53. Jacquemier J, Charpin C: [Reproducibility of histoprognostic grades of invasive breast cancer]. Ann Pathol 1998, 18:385-390

54. Chowdhury N, Pai MR, Lobo FD, Kini H, Varghese R: Interobserver variation in breast cancer grading: a statistical modeling approach. Anal Quant Cytol Histol 2006, 28:213-218

55. Page DL, Gray R, Allred DC, Dressler LG, Hatfield AK, Martino S, Robert NJ, Wood WC: Prediction of node-negative breast cancer outcome by histologic grading and S-phase analysis by flow cytometry: an Eastern Cooperative Oncology Group Study (2192). Am J Clin Oncol 2001, 24:10-18

56. Longacre TA, Ennis M, Quenneville LA, Bane AL, Bleiweiss IJ, Carter BA, Catelano E, Hendrickson MR, Hibshoosh H, Layfield LJ, Memeo L, Wu H, O'malley FP: Interobserver agreement and reproducibility in classification of invasive breast carcinoma: an $\mathrm{NCl}$ breast cancer family registry study. Mod Pathol 2006, 19:195-207

57. Boiesen P, Bendahl PO, Anagnostaki L, Domanski H, Holm E, Idvall I, Johansson S, Ljungberg O, Ringberg A, Ostberg G, Fernö M: Histologic grading in breast cancer--reproducibility between seven pathologic departments. South Sweden Breast Cancer Group. Acta Oncol 2000, 39:41-45.

58. Sikka M, Agarwal S, Bhatia A: Interobserver agreement of the Nottingham histologic grading scheme for infiltrating duct carcinoma breast. Indian $J$ Cancer 1999, 36:149-153.
59. Hopton DS, Thorogood J, Clayden AD, MacKinnon D: Observer variation in histological grading of breast cancer. Eur J Surg Oncol 1989, 15:21-23.

60. European Commission: European Guidelines for Quality Assurance in Mammography Screening. Luxembourg: Office for Official Publications of the European Communities; 1996.

61. Robbins P, Pinder S, de Klerk N, Dawkins H, Harvey J, Sterrett G, Ellis I, Elston C Histological grading of breast carcinomas: a study of interobserver agreement. Hum Pathol 1995, 26:873-879.

62. Pathology and genetics of tumors of the breast and female genital organs. In World Health Organization Classification of Tumors. Edited by Tavassoli FA, Devilee P. Lyon: IACR Press; 2003

63. Lusa L, McShane LM, Reid JF, De Cecco L, Ambrogi F, Biganzoli E, Gariboldi M, Pierotti MA: Challenges in projecting clustering results across gene expression-profiling datasets. J Natl Cancer Inst 2007, 99:1715-1723.

64. Nuyten DS, Chang HY, Brown PO, Van de Vijver MJ: Reproducibility of molecular portraits in early stage breast cancer. Breast Cancer Research 2005, 7 (Suppl 2):P4.

65. Chang HY, Nuyten DS, Sneddon JB, Hastie T, Tibshirani R, Sørlie T, Dai H, He YD, van't Veer $L J$, Bartelink $H$, van de Rijn M, Brown PO, van de Vijver MJ: Robustness, scalability, and integration of a wound-response gene expression signature in predicting breast cancer survival. Proc Natl Acad Sci USA 2005, 102:3738-3743.

66. Sotiriou C, Wirapati P, Loi S, Harris A, Fox S, Smeds J, Nordgren H, Farmer P, Praz V, Haibe-Kains B, Desmedt C, Larsimont D, Cardoso F, Peterse H, Nuyten D, Buyse M, Van de Vijver MJ, Bergh J, Piccart M, Delorenzi M: Gene expression profiling in breast cancer: understanding the molecular basis of histologic grade to improve prognosis. J Natl Cancer Inst 2006, 98:262-272.

67. Natrajan R, Lambros MB, Geyer FC, Marchio C, Tan DS, Vatcheva R, Shiu KK, Hungermann D, Rodriguez-Pinilla SM, Palacios J, Ashworth A, Buerger H, Reis-Filho JS: Loss of $16 \mathrm{q}$ in high grade breast cancer is associated with estrogen receptor status: Evidence for progression in tumors with a luminal phenotype? Genes Chromosomes Cancer 2009, 48:351-365.

68. Yu K, Lee CH, Tan PH, Hong GS, Wee SB, Wong CY, Tan P: A molecular signature of the Nottingham prognostic index in breast cancer. Cancer Res 2004, 64:2962-2968.

69. Lu X, Lu X, Wang ZC, Iglehart JD, Zhang X, Richardson AL: Predicting features of breast cancer with gene expression patterns. Breast Cancer Res Treat 2008, 108:191-201

70. Dunkler D, Michiels S, Schemper M: Gene expression profiling: does it add predictive accuracy to clinical characteristics in cancer prognosis? Eur J Cancer 2007 43:745-751.

71. Eden P, Ritz C, Rose C, Ferno M, Peterson C: 'Good Old' clinical markers have similar power in breast cancer prognosis as microarray gene expression profilers. Eur J Cancer 2004, 40:1837-1841.

72. van de Vijver MJ, He YD, van't Veer LJ, Dai H, Hart AA, Voskuil DW, Schreiber GJ, Peterse IL, Roberts C, Marton MJ, Parrish M, Atsma D, Witteveen A, Glas A, Delahaye L, van der Velde T, Bartelink H, Rodenhuis S, Rutgers ET, Friend SH, Bernards R: A gene-expression signature as a predictor of survival in breast cancer. N Engl J Med 2002, 347:1999-2009.

73. Bueno-de-Mesquita JM, Sonke GS, van de Vijver MJ, Linn SC: Additional value and potential use of the 70-gene prognosis signature in nodenegative breast cancer in daily clinical practice. Ann Oncol 2009 Dec 2 [Epub ahead of print].

74. Hornberger J, Cosler LE, Lyman GH: Economic analysis of targeting chemotherapy using a 21-gene RT-PCR assay in lymph-node-negative, estrogen-receptor-positive, early-stage breast cancer. Am J Manag Care 2005, 11:313-324.

75. Blamey RW, Pinder SE, Ball GR, Ellis IO, Elston CW, Mitchell MJ, Haybittle JL: Reading the prognosis of the individual with breast cancer. Eur I Cancer 2007, 43:1545-1547.

76. Abd El-Rehim DM, Ball G, Pinder SE, Rakha E, Paish C, Robertson JF Macmillan D, Blamey RW, Ellis IO: High-throughput protein expression analysis using tissue microarray technology of a large well-characterised series identifies biologically distinct classes of breast cancer confirming recent CDNA expression analyses. Int $J$ Cancer 2005, 116:340-350

77. Elston CW: The assessment of histological differentiation in breast cancer. Aust N Z J Surg 1984, 54:11-15.

78. Davis BW, Gelber RD, Goldhirsch A, Hartmann WH, Locher GW, Reed R, Golouh R, Süe-Söderbergh J, Holloway L, Russell I, Rudenstam CM: Prognostic significance of tumor grade in clinical trials of adjuvant 
therapy for breast cancer with axillary lymph node metastasis. Cancer 1986, 58:2662-2670.

79. Le Doussal V, Tubiana-Hulin M, Friedman S, Hacene K, Spyratos F, Brunet M: Prognostic value of histologic grade nuclear components of Scarff-BloomRichardson (SBR). An improved score modification based on a multivariate analysis of 1262 invasive ductal breast carcinomas. Cancer 1989, 64:1914-1921.

80. Balslev I, Axelsson CK, Zedeler K, Rasmussen BB, Carstensen B, Mouridsen HT: The Nottingham Prognostic Index applied to 9,149 patients from the studies of the Danish Breast Cancer Cooperative Group (DBCG). Breast Cancer Res Treat 1994, 32:281-290.
81. Thomas JS, Kerr GR, Jack WJ, Campbell F, McKay L, Pedersen HC, Kunkler IH, Cameron DA, Chetty U, Bartlett JM: Histological grading of invasive breast carcinoma--a simplification of existing methods in a large conservation series with long-term follow-up. Histopathology 2009, 55:724-731.

doi:10.1186/bcr2607

Cite this article as: Rakha $E A$, et al.: Breast cancer prognostic classification in the molecular era: the role of histological grade. Breast Cancer Research 2010, 12:207 